\title{
Endoplasmic reticulum stress activates autophagy but not the proteasome in neuronal cells: implications for Alzheimer's disease
}

\author{
DAT Nijholt ${ }^{1}$, TR de Graaf ${ }^{1}$, ES van Haastert ${ }^{2}$, A Osório Oliveira ${ }^{1}$, CR Berkers ${ }^{3}$, R Zwart ${ }^{1}$, H Ovaa ${ }^{3}$, F Baas ${ }^{1,4}$, JJM Hoozemans ${ }^{2}$ \\ and W Scheper, ${ }^{\star}, 4$
}

Protein folding stress in the endoplasmic reticulum (ER) may lead to activation of the unfolded protein response (UPR), aimed to restore cellular homeostasis via transcriptional and post-transcriptional mechanisms. ER stress is also reported to activate the ER overload response (EOR), which activates transcription via NF- $\kappa$ B. We previously demonstrated that UPR activation is an early event in pre-tangle neurons in Alzheimer's disease (AD) brain. Misfolded and unfolded proteins are degraded via the ubiquitin proteasome system (UPS) or autophagy. UPR activation is found in AD neurons displaying both early UPS pathology and autophagic pathology. Here we investigate whether activation of the UPR and/or EOR is employed to enhance the proteolytic capacity of neuronal cells. Expression of the immunoproteasome subunits $\beta 2 i$ and $\beta 5 i$ is increased in AD brain. However, expression of the proteasome subunits is not increased by the UPR or EOR. UPR activation does not relocalize the proteasome or increase overall proteasome activity. Therefore proteasomal degradation is not increased by ER stress. In contrast, UPR activation enhances autophagy and LC3 levels are increased in neurons displaying UPR activation in AD brain. Our data suggest that autophagy is the major degradational pathway following UPR activation in neuronal cells and indicate a connection between UPR activation and autophagic pathology in AD brain.

Cell Death and Differentiation (2011) 18, 1071-1081; doi:10.1038/cdd.2010.176; published online 21 January 2011

The Alzheimer's disease (AD) brain is characterized by the accumulation of extracellular plaques composed of Amyloid beta $(\mathrm{A} \beta)$ and intracellular neurofibrillary tangles (NFTs) composed of hyperphosphorylated tau. ${ }^{1}$ We have previously shown that the unfolded protein response (UPR) is activated in $A D$ neurons that contain diffusely distributed hyperphosphorylated tau. ${ }^{2}$ The UPR is a stress response that is activated upon the accumulation of misfolded or unfolded proteins in the endoplasmic reticulum (ER). ${ }^{3,2}$ It is aimed at restoring homeostasis by attenuating overall protein translation, and by promoting transcription and translation of specific genes involved in protein homeostasis. Another, less-wellstudied, ER stress response is the ER overload response (EOR), which signals via NF- $\kappa \mathrm{B}^{4,5}$

The degradation of aberrant ER proteins is mediated by a process termed ER-associated degradation (ERAD). ${ }^{6}$ Activation of the UPR induces a number of ERAD-related genes. ${ }^{7}$ ERAD involves export of the misfolded proteins via specific channels in the ER membrane and subsequent degradation by the cytosolar ubiquitin proteasome system (UPS). ${ }^{6}$ The proteasome 205 catalytic core comprises three catalytically active beta $(\beta)$ type subunits $\beta 1, \beta 2$ and $\beta 5$, which convey peptidyl-glutamyl peptide-hydrolyzing- (PGPH), trypsin- and chymotrypsin-like activity. The constitutive $\beta$ subunits can be exchanged for the immuno subunits $\beta 1 \mathrm{i}, \beta 2 \mathrm{i}$ and $\beta 5 \mathrm{i}$ under the influence of NF- $\kappa$ B signalling, for example during antigen presentation. ${ }^{8}$ The immunoproteasome displays slightly altered catalytic activity; for example, it is capable of degrading tau faster and more efficiently in vitro. ${ }^{9}$ Changes in proteasome activity are reported for several neurodegenerative disorders, including $A D^{10,11}$ and Parkinson's disease (PD). ${ }^{12}$ Systemic administration of proteasome inhibitors in rats causes a PD-like phenotype, with $\alpha$-synuclein and ubiquitin-positive inclusion bodies and neurodegeneration in the substantia nigra. ${ }^{12}$ This suggests that dysfunction of the UPS can lead to neurodegeneration. Interestingly, an increase in the immunoproteasome subunit $\beta 1 \mathrm{i}$ was observed in the AD brain, ${ }^{13}$ a change in proteasome subunit composition that is associated with increased chymotryptic activity. ${ }^{14,13}$ This could be a response to the accumulation of substrates that require a different proteolytic specificity in order to be degraded.

Another major degradational system reported to be activated by ER stress in vitro is autophagy. ${ }^{15-17}$ During autophagy, a double membrane is wrapped around an organelle or protein aggregate and this autophagosome subsequently fuses with a lysosome, forming an autophagolysosome where degradation takes place. Mice deficient in

\footnotetext{
${ }^{1}$ Department of Genome Analysis, Academic Medical Center, University of Amsterdam, Amsterdam, The Netherlands; ${ }^{2}$ Department of Pathology, VU University Medical Center, Amsterdam, The Netherlands; ${ }^{3}$ Division of Cell Biology, The Netherlands Cancer Institute, Amsterdam, The Netherlands and ${ }^{4}$ Department of Neurology, Academic Medical Center, University of Amsterdam, Amsterdam, The Netherlands

${ }^{*}$ Corresponding author: W Scheper, Neurogenetics Laboratory, Academic Medical Center, PO Box 22660, 1100 DE Amsterdam, The Netherlands.

Tel: + 3120 5664959; Fax: + 3120 5669312; E-mail: w.scheper@amc.uva.nl

Keywords: Alzheimer's disease; unfolded protein response; ubiquitin proteasome system; autophagy

Abbreviations: AD, Alzheimer's disease; HD, Huntington's disease; ER, endoplasmic reticulum; UPR, unfolded protein response; EOR, ER overload response; UPS, ubiquitin proteasome system; NFT, neurofibrillary tangle; A $\beta$, Amyloid beta; ERAD, ER-associated degradation; GVD, granulovacuolar degeneration

Received 08.7.10; revised 17.11.10; accepted 29.11.10; Edited by A Verkhraski; published online 21.1.11
} 
autophagin (atg) $5^{18}$ or atg $7^{19}$ accumulate ubiquitin-positive cytoplasmic aggregates and show neurodegeneration. Healthy neurons only rarely show autophagic structures, whereas many autophagic vacuoles can be observed in $A D$ neuronal cell bodies and dystrophic neurites. ${ }^{20} \mathrm{~A}$ commonly observed lesion in the AD brain is granulovacuolar degeneration (GVD), which is considered to be a disturbed autophagic process. ${ }^{21}$ It is typically seen in the cytoplasm of the pyramidal neurons of the cornu ammonis (CA) 1 and subiculum of the hippocampus, sites that also show extensive tau pathology. ${ }^{2}$ GVD consists of electron-dense granules surrounded by a clear vacuole that measure $2-4 \mu \mathrm{M}$ in size. The presence of GVD in this region of the hippocampus correlates well with the diagnosis of $A D$.

The UPR is activated as an early response in neurons in $A D$ and may be a signal to enhance the degradational capacity of the affected neuron. Both the UPS and autophagy have a role in the degradation of aberrant proteins in neurodegenerative disorders and have been implicated in AD. UPR-positive neurons in the $A D$ hippocampus are associated with early UPS pathology, in the form of ubiquitin-positive, p62-negative inclusion bodies, and show autophagic pathology in the form of GVD. ${ }^{2}$ Here we investigate the role of these two degradational systems during ER stress in vitro and in human $A D$ brain material. All hypotheses tested in this study are visualized in Figure $8 a$.

\section{Results}

Immunoproteasome subunit expression is increased in the AD brain. Previously we reported that UPR activation is predominantly observed in AD hippocampus. ${ }^{3,2}$ Therefore, we evaluated expression of the immunoproteasome subunits $\beta 2 \mathrm{i}$ and $\beta 5 \mathrm{i}$ in this region of a cohort of $A D$ and age-matched non-demented controls using immunohistochemistry. Both $\beta 2 \mathrm{i}$ and $\beta 5 \mathrm{i}$ expression is seen in $A D$ and control hippocampus in neurons, glial cells and endothelial cells, based on morphological assessment (Figures 1a-l). Increased $\beta 1 \mathrm{i}$ reactivity in these cell types in $A D$ and aged hippocampus was previously described. ${ }^{13}$ Here we show a granular pattern of $\beta 2 i$ reactivity in neurons, the intensity of which increases with Braak stages for neurofibrillary changes. No clear association is observed between $\beta 2 \mathrm{i}$ immunoreactivity in neurons and the local presence of $\mathrm{A} \beta$ plaques and neurofibrillary changes (data not shown). A moderate increase in $\beta 5 \mathrm{i}$ immunoreactivity in neurons is observed in high Braak stages. However, there is a remarkable increase in the number of glial cells that are immunoreactive for $\beta 5 \mathrm{i}$ in higher Braak stages. Double immunolabelling using $\beta 5 \mathrm{i}$ and a marker for astrocytes (GFAP) or microglia (Iba1) shows that $\beta 5 i$ is expressed in both astrocytes and microglia (Figures $1 \mathrm{~m}$ and $n$ ). Our data show that expression of the immunoproteasome subunits is increased in the AD hippocampus.

ER stress: effects on proteasome subunit expression. We next investigated whether UPR activation is responsible for the increased expression of the immunoproteasome in an in vitro model. Differentiated neuronal SK-N-SH cells were treated with increasing concentrations of tunicamycin (Tm) to chemically induce the UPR. No change in mRNA levels of the non-catalytic $\alpha$ subunits $\mathrm{HC} 5$ and $\mathrm{C} 7$ or the constitutive catalytic $\beta$ subunits $\beta 1, \beta 2$ and $\beta 5$ is observed after induction of ER stress (Figure $2 a$ ). Figure $2 b$ shows that the UPR is active under these conditions, as mRNA levels of the UPR-responsive genes $\mathrm{BiP}$ and $\mathrm{CHOP}$ are increased 25.0-fold \pm 5.5 and 18.8 -fold \pm 2.4 , respectively. ER stress increases expression of the immuno subunits $\beta 5 \mathrm{i}$ (alternative transcript $\beta 5 \mathrm{i}-1$ : 3.9-fold \pm 0.4 and $\beta 5 \mathrm{i}-2$ : 4 .1-fold \pm 0.7 ) and, to a lesser extent, $\beta 2$ i (2.0-fold \pm 0.3$)$. As a positive control for induction of the immuno $\beta$ subunits, treatment with $\gamma$ IFN was used (5.9-fold $\pm 0.6,132.0$-fold \pm 22.5 and 576.8 -fold \pm 81.3 for $\beta 2 \mathrm{i}, \beta 5 \mathrm{i}-1$ and $\beta 5 \mathrm{i}-2$, respectively). The UPR-responsive genes are not regulated by $\gamma$ IFN. The $\beta 1 \mathrm{i}$ subunit is increased by $\gamma \mathrm{IFN}$, but is below the detection limit under control or Tm conditions in our model and is therefore not included in Figure $2 \mathrm{a}$.

In accordance with our quantitative PCR (qPCR) data, $\gamma$ IFN results in increased protein levels of $\beta 2 \mathrm{i}$ and $\beta 5 \mathrm{i}$ ( $\sim 35$-fold), but not of $\beta 2$. We find no regulation of the $\beta 2 \mathrm{i}, \beta 5 \mathrm{i}$ and $\beta 2$ proteins levels by $\mathrm{Tm}$. The increase in BiP levels indicates that the UPR is active under these conditions ${ }^{3}$ (Figure 2). To exclude the effects of different kinetics, we extended the Tm treatment to $48 \mathrm{~h}$, but this did not change the outcome (not shown). Combined, we find moderate upregulation of the immunoproteasome subunits $\beta 2 i$ and $\beta 5 i$ at the mRNA level during ER stress, but this does not lead to a change at the protein level.

ER stress does not affect $\boldsymbol{\beta} 2 \mathrm{i}$ promoter activity. Most UPR-regulated genes contain ER stress-responsive elements (ERSEs) in their promoter. No ERSEs are found in the immuno $\beta$ subunit proximal promoters, but all contain a consensus NF- $\kappa \mathrm{B}$ site that is expected to be activated by the EOR if it is functional (Figure $3 a$ ). To directly investigate the immunoproteasome $\beta$ subunit promoter $\mathrm{NF}-\kappa \mathrm{B}$ responsiveness and the effect of ER stress on promoter activity, we cloned the promoter of $\beta 2 \mathrm{i}$ upstream of the luciferase gene. The $\beta 2 \mathrm{i}$ subunit is upregulated in AD postmortem material (Figure 1), is upregulated by $\gamma \mathrm{IFN}$ in our qPCR and western blot experiments (Figure 2) and contains a consensus NF- $\kappa$ B-binding site (Figure 3a). HEK293 cells were transfected with the $\beta 2 \mathrm{i}$ promoter-luciferase construct and treated with $\gamma \mathrm{IFN}$ or Tm for $16 \mathrm{~h}$. The BiP promoterluciferase construct was used as a control for induction of the UPR. $^{22}$ The activity of the $\beta 2 \mathrm{i}$ promoter is increased ( $\sim 2$-fold) by $\gamma$ IFN, but, as expected, there is no change in $\mathrm{BiP}$ promoter activity because it does not contain an NF- $\kappa \mathrm{B}$ element (Figure $3 \mathrm{~b}$ ). Abolishment of the $\beta 2 \mathrm{i} N \mathrm{~F}-\kappa \mathrm{B}-\mathrm{binding}$ site by site-directed mutagenesis prevents $\gamma \mathrm{IFN}$-mediated regulation, demonstrating that the $\beta$ 2i promoter is responsive to $\mathrm{NF}-\kappa \mathrm{B}$ and that the $\mathrm{NF}-\kappa \mathrm{B}$ signalling route is functional in this model. In contrast, ER stress induced by $\mathrm{Tm}$ has no effect on $\beta 2 \mathrm{i}$ promoter activity, but does (as expected) increase BiP promoter activity (Figure 3b). Although $\beta 5 \mathrm{i}$ promoter responsiveness was not directly investigated, our combined data indicate that expression of the immunoproteasome $\beta$ subunits is not regulated by the UPR or EOR pathway of the ER stress response. 
$\beta 2 i$

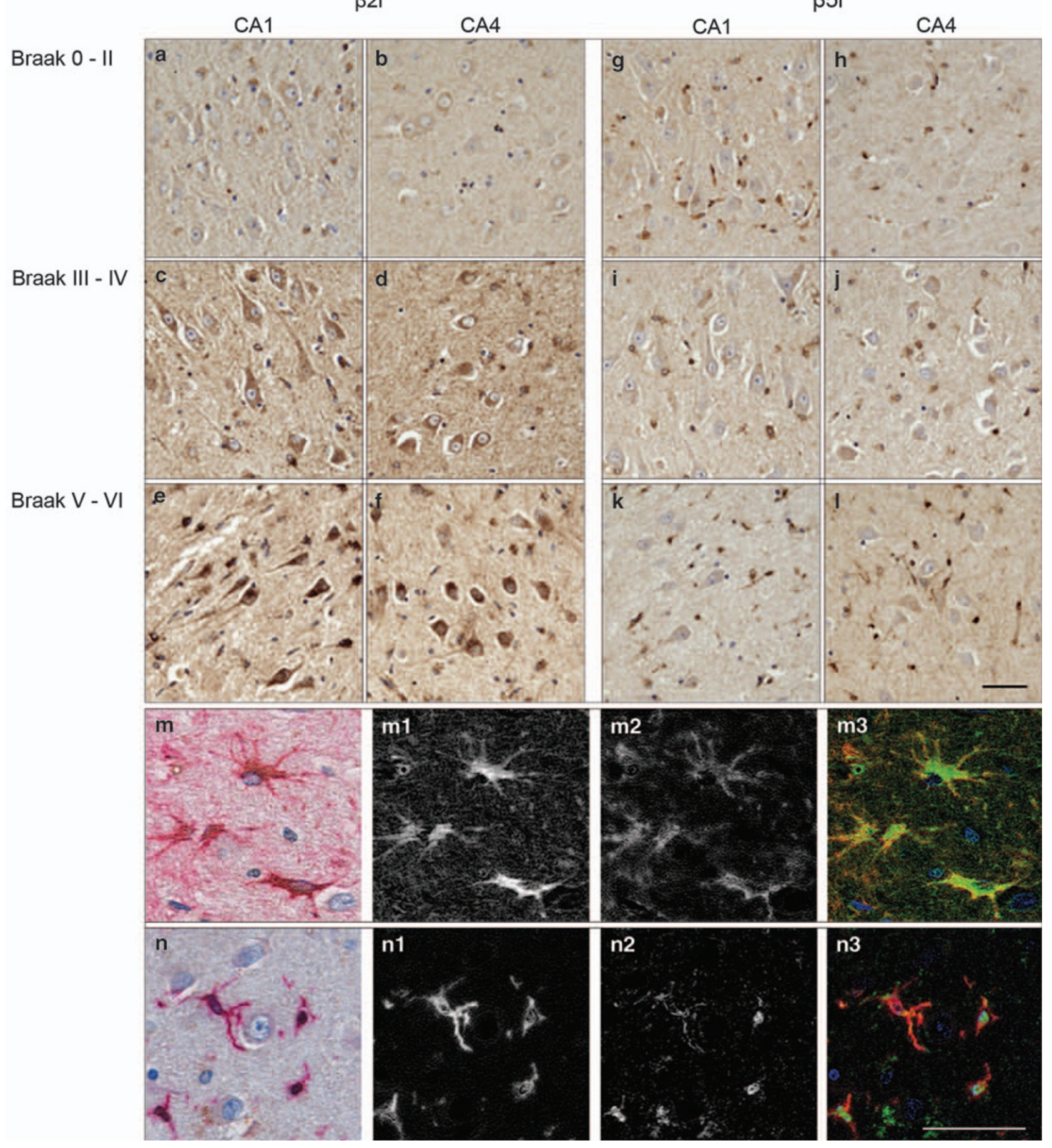

Figure 1 Expression of $\beta 2 \mathrm{i}$ and $\beta 5 \mathrm{i}$ immunoproteasome subunits is increased in $\mathrm{AD}$ hippocampus. Representative immunohistochemical stainings for $\beta 2 \mathrm{i}(\mathrm{a}-\mathrm{f})$ and $\beta 5 \mathrm{i}$ $(\mathbf{g}-\mathbf{l})$ in the hippocampal CA1 and CA4 region of a non-demented control Braak 1/0 (CA1 (a and g), CA4 (b and $\mathbf{h})$ ), AD Braak 3C (CA1 (c and i), CA4 (d and j)) and AD Braak $5 \mathrm{C}$ (CA1 (e and k), CA4 (f and I)) case. Reactivity to $\beta 2$ is present in neurons, glial and endothelial cells, and increases with the Braak stage for NFTs. Double immunolabelling shows $\beta 5$ i expression in astrocytes using GFAP as a marker $(\mathrm{m})$ and microglia using lba1 as a marker $(\mathrm{n})$ in AD hippocampus. Nuclei were counterstained with hematoxylin (blue). The GFAP/lba1 and $\beta 5$ i signals were spectrally unmixed and are shown separately ( $\mathrm{m} / \mathrm{n} 1$ and $\mathrm{m} / \mathrm{n} 2$, respectively) and as a merge with artificial colors (m/n 3: GFAP/ Iba1: red; $\beta 5$ i: green). Scale bar: $50 \mu \mathrm{M}$

ER stress has no effect on $\beta 5 i$ subunit localization. Several studies indicate enrichment of the immunoproteasome at the ER membrane, ${ }^{23,24}$ which may facilitate rapid degradation of proteins exported out of the ER by ERAD. Relocalization in response to a stimulus may therefore present another level of regulation. We investigated 


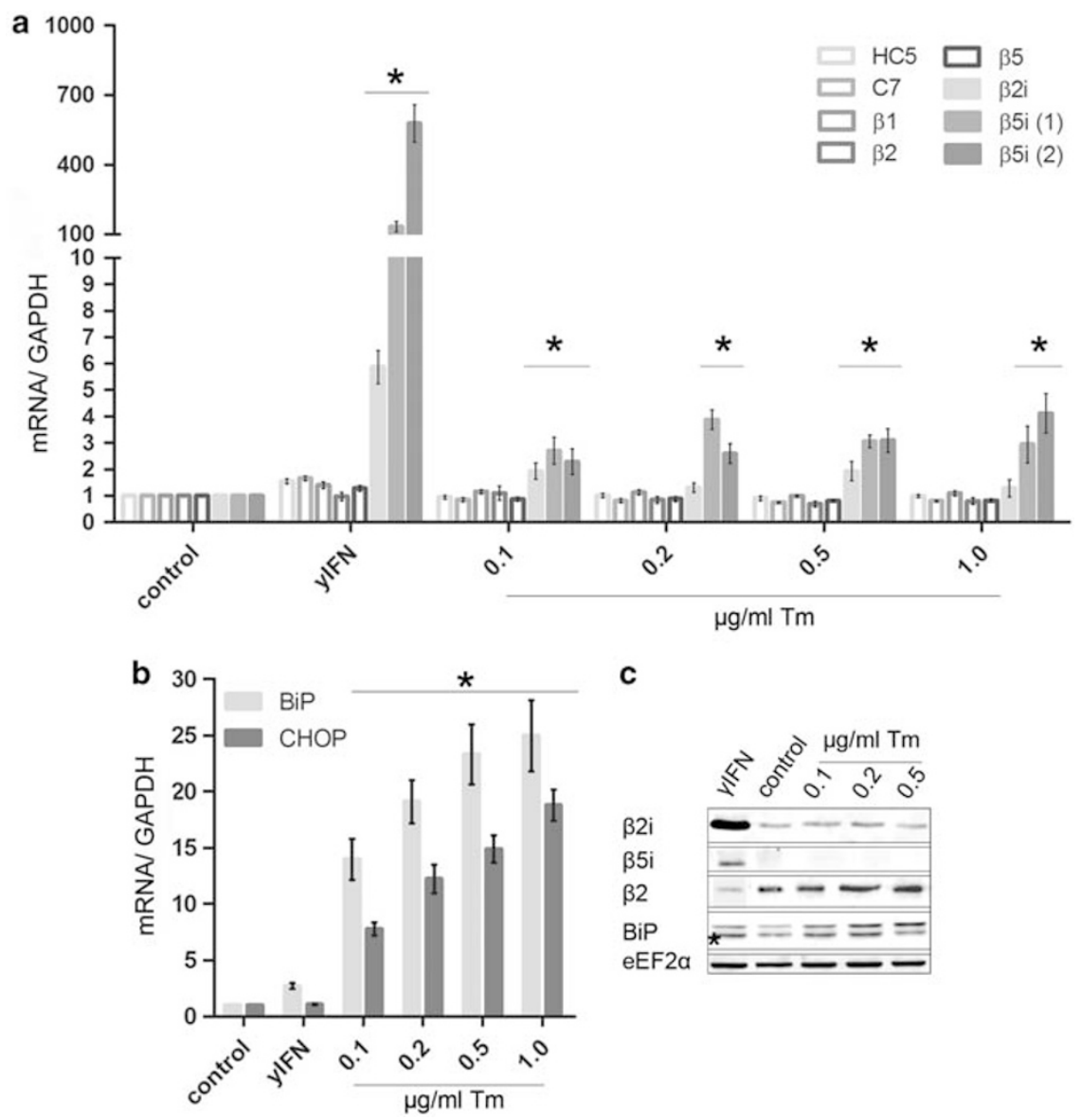

Figure 2 Effects of ER stress on proteasome $\beta$ subunit expression. Differentiated SK-N-SH cells were treated with $\gamma \mathrm{IFN}$ or Tm for $16 \mathrm{~h}$. Relative mRNA and protein levels of proteasome subunits were determined using q-PCR and western blotting. (a) Normalized mRNA expression levels of the proteasome subunits $\alpha$ (HC5 and C7) and $\beta$ $(\beta 1, \beta 2, \beta 5, \beta 2 i$ and $\beta 5 i)$. (b) ER stress-responsive genes BiP and CHOP. Expression levels were normalized to GAPDH mRNA levels. Data are mean \pm S.D. from triplicate observations of a representative experiment. Asterisks indicate significant differences compared with control levels $(P<0.05)$. (c) Western blot analysis with antibodies directed against the $\beta 5 \mathrm{i}, \beta 2 \mathrm{i}$ and $\beta 2$ subunits and the ER stress-responsive protein BiP. Asterisk indicates cross-reactivity of the BiP antibody with Hsc70. The expression levels of eEF2 $\alpha$ are indicated as loading control. Blots from a representative experiment are shown

localization of the $\beta 5 \mathrm{i}$ subunit in differentiated SK-N-SH cells during ER stress. Because the great majority of $\beta$ subunits is incorporated in proteasome complexes, this reflects subunits in actual proteasomes. ${ }^{25}$ Cells were double stained using antibodies directed against the $\beta 5 i$ proteasome subunit and calnexin, an integral ER membrane protein (Figure 4). Reactivity to $\beta 5 \mathrm{i}$ and its colocalization with calnexin are increased by $\gamma \mathrm{IFN}$, indicating that the increased $\beta 5$ i protein localizes at least in part to the ER membrane. Treatment with $\mathrm{Tm}$ does not change the $\beta 5 \mathrm{i}$ intensity level, confirming our western blot data (Figure 2c). In addition, the localization of $\beta 5 \mathrm{i}$ is not affected by activation of the UPR. Although increased immunoreactivity to $\beta 2 i$ and $\beta 5 i$ is observed in $A D$, our in vitro studies suggest that UPR activation is not responsible for this induction.

ER stress does not increase proteasome activity. During ER stress, the demand for proteolytic activity is increased. We show that the proteasome $\beta$ subunits are not subject to classical ER stress responsive regulation (Figures 2 and 3), nor is relocalization to the ER observed (Figure 4). However, this does not exclude regulation of the proteolytic activity of the proteasome. Using an unstable fluorescent substrate, a small decrease in proteasome activity was previously observed under conditions of ER stress. ${ }^{26}$ This reporter system has the disadvantage that it depends on factors besides proteasome activity (e.g. transcription and translation). This method could yield inaccurate results, especially during ER stress, when translation in general is inhibited. To directly investigate the effect of ER stress on total proteasome activity, a fluorescent proteasome activity probe was used that covalently binds to the catalytic subunits of active proteasomes. ${ }^{27}$ Differentiated neuronal SK-N-SH cells were treated with $\mathrm{Tm}$ and subsequently incubated with the fluorescent reporter, and the fluorescent signal for the different subunits was visualized by SDS-PAGE and quantified (Figures $5 \mathrm{a}$ and $\mathrm{b}$ ). We find no detectable activity of the immunoproteasome. ER stress has little to no effect on proteasome activity in our cell model. A decrease in activity is observed at the highest concentration of Tm used; however, this might have been caused by $\mathrm{Tm}$-induced toxicity. 


\begin{tabular}{|l|l|l|l|r|}
\hline $\begin{array}{l}\text { 20S } \beta \text {-type } \\
\text { subunit }\end{array}$ & Human gene & $\begin{array}{l}\text { ERSE binding } \\
\text { motif }\end{array}$ & $\begin{array}{l}\text { NF-kB binding } \\
\text { motif }\end{array}$ & Location \\
\hline$\beta 1$ & PSMB6 & None & None & \\
\hline$\beta 2$ & PSMB7 & None & None & \\
\hline$\beta 5$ & PSMB5 & None & None & \\
\hline$\beta 1 i$ & PSMB9 & None & $5^{\circ}$ GGGCTTTTGA 3. & -211 \\
\hline$\beta 2 i$ & PSMB10 & None & $5^{\circ}$ GGGGCTTGCC 3. & -123 \\
\hline$\beta 5 i$ & PSMB8 & None & $5^{\circ}$ GGGACATCAC 3. & -124 \\
\hline
\end{tabular}

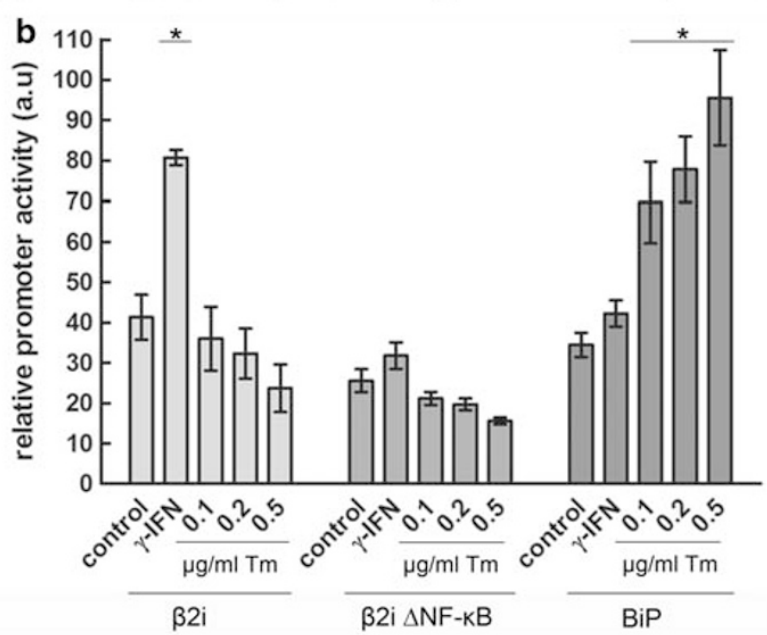

Figure 3 ER stress does not increase $\beta 5$ i promoter activity. (a) Representation of binding sites for ER stress-responsive transcription factors in the promoter regions of the $\beta$ subunits of the proteasome. No classical ERSE-binding motifs are identified; in contrast putative NF- $\kappa \mathrm{B}(\mathrm{p} 50-\mathrm{p} 65)$ binding sites are present in the proximal promoter region of all the immuno $\beta$ subunits. The location of the binding site is indicated relative to the transcription start site. (b) Relative activity of $\beta 5 \mathrm{i}, \beta 5 \mathrm{i}$ $\mathrm{NF}-\kappa \mathrm{B}$-binding site mutant $(\beta 5 \mathrm{i} \Delta \mathrm{NF}-\kappa \mathrm{B})$ and BiP promoters in HEK293 cells. Promoter activities were determined using a luciferase-renilla assay as described in Materials and methods in the presence or absence of $\gamma \mathrm{IFN}$ or Tm at the indicated concentrations for $16 \mathrm{~h}$. Data are mean \pm S.D. from triplicate observations of a representative experiment. Asterisks indicate significant differences compared with control $(P<0.05)$

LC3 processing is increased during ER stress. Our data show that the UPS is not upregulated by the UPR. Because during ER stress there is an increased presence of misfolded proteins, this may lead to accumulation and toxicity if they are not degraded. In contrast to the massive accumulation of polyubiquitinated proteins when using proteasome inhibition, different types of ER stress inducers (Tm, thapsigargin (Th) and 2-deoxyglucose (2DG)) do not lead to accumulation in neuronal cells (Figure $6 \mathrm{a}$, upper panel). This may imply that the proteasome is redundant during ER stress, but it cannot be excluded that basal proteasome activity is still sufficient to deal with the misfolded protein load during ER stress. In case of the latter, complete inhibition of proteasome activity should induce a massive UPR. We have previously demonstrated that proteasome inhibition does not induce a robust ER stress response, ${ }^{28}$ suggesting that proteasomal activity is dispensable to resolve ER stress under conditions of UPR activation.

ER stress was previously shown to be able to induce autophagy in vitro. ${ }^{29,15}$ To determine whether ER stress increases autophagy in our cell model, we measured LC3-II levels induced by various ER stressors (Figure 6a, middle panel). The amount of LC3-II directly correlates with the amount of autophagosomes. ${ }^{30} \mathrm{Tm}$, Th and 2DG increase LC3-II levels and the LC3-II/LC3-I ratio (Figure 6b), indicating that autophagy becomes more active under conditions of ER stress. This suggests that autophagy is the preferred route for degradation of proteins during UPR activation.

LC3 levels are increased in pPERK-positive neurons in the AD brain. The levels of $L C 3$ in $A D$ hippocampus were evaluated using immunohistochemistry. LC3 reactivity is abundant in hippocampal neurons in AD (Figure 7a) and control subjects (data not shown), whereas low intensity is observed in non-neuronal cells. The intensity of reactivity to LC3 is increased in AD in neurons showing GVD (Figures 7b and c). The staining of LC3 is observed throughout the cell body, but appears to be more intense at the edges of the vacuoles, corroborating that GVD is related to autophagosomes. Occasionally, reactivity with the granular material inside the vacuole is observed. We have previously shown that UPR activation is associated with GVD in the AD hippocampus, ${ }^{3,2}$ and therefore we used double immunohistochemistry with the UPR marker phosphorylated PERK (pPERK) to investigate the connection between LC3 and UPR activation. LC3 intensity is increased in neurons displaying pPERK reactivity (Figure 7d). These data show a clear correlation between UPR activation and the autophagy marker LC3 in human AD hippocampus. This corroborates our in vitro data demonstrating that the UPR preferentially activates the autophagy pathway and indicates that this response also occurs in vivo.

\section{Discussion}

In this study, we investigated the effects of ER stress on the two major degradational systems in the cell: the UPS and the autophagy pathway, and their relationship with AD (Figure 8).

Increased expression of the immunoproteasome has been found in several neurodegenerative diseases ${ }^{13,31,32}$ (see also Figure 1). Increased expression of $\beta 2 i$ and $\beta 5 i$ was observed in affected brain areas of Huntington's disease (HD) patients and a mouse model, ${ }^{31}$ but could not be recapitulated in a HD cell model, ${ }^{33}$ suggesting that a non-cell-autonomous mechanism is responsible for this induction. In analogy, we found that NF- $\kappa \mathrm{B}$ is not activated by the EOR in neuronal cells. In the first report on the EOR, retention of a viral protein in the ER induced a robust NF- $\kappa$ B response in HEK293 cells. ${ }^{4}$ Another study indicated that chemical ER stress induction also elicits an NF- $\kappa$ B response. ${ }^{5}$ However, in our study we found no ER stress-mediated regulation of the NF- $k B$ responsive subunits of the immunoproteasome in HEK293 or neuronal SK-N-SH cells. A small transcriptional response to ER stress was observed; however, this was not sufficient to result in increased protein levels, indicating that the EOR is not effective in our models. We used the endogenous $\beta 2 \mathrm{i}$ promoter that contains a single NF- $\kappa \mathrm{B}$ responsive element, whereas in the previous work a construct containing five NF- $\kappa$ B-binding sites was employed. A small induction of $\mathrm{NF}-\kappa \mathrm{B}$ may thus lead to increased activity of this reporter, whereas induction of the endogenous $\beta 2 i$ promoter will have a higher threshold for transcriptional activation and is unlikely to reach the level required to yield changes at the protein level. 


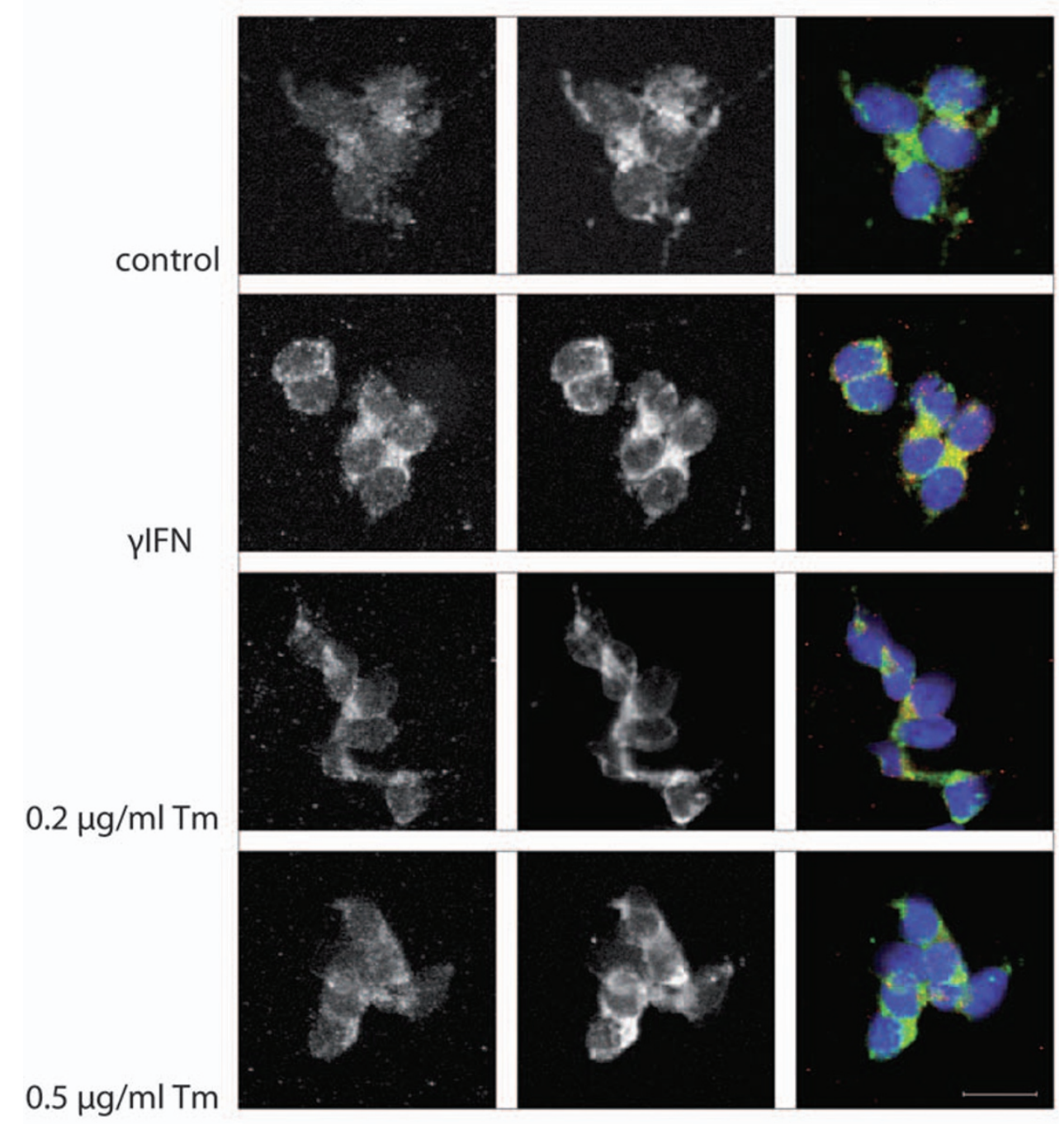

Figure 4 ER stress does not influence $\beta 5$ i localization. Differentiated SK-N-SH cells were treated with $\gamma$ IFN or Tm for $16 \mathrm{~h}$ at the indicated concentrations compared with a non-treated control. Confocal pictures of the localization of $\beta 5 \mathrm{i}$ (left hand panel) and calnexin (middle panel) by immunofluorescence are shown. An overlay of $\beta 5 \mathrm{i}$ (red), calnexin (green) and DAPI nuclear counterstain (blue) is shown on the right. Scale bar: $20 \mu \mathrm{M}$

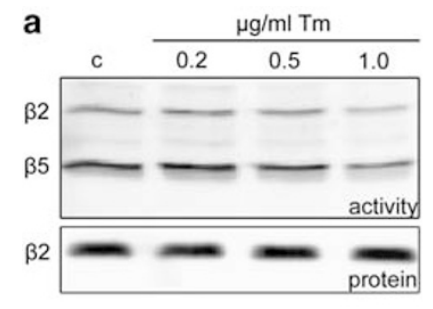

b

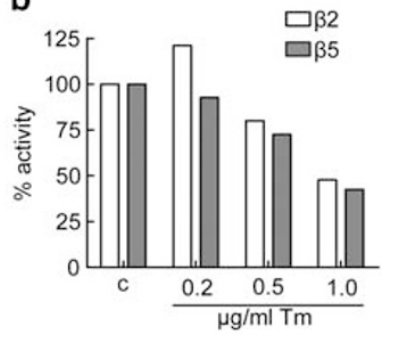

Figure 5 ER stress does not increase proteasome activity. Differentiated SK-N-SH cells were treated with indicated concentrations of $\mathrm{Tm}$ for $16 \mathrm{~h}$ and incubated with the $\mathrm{Me}_{4}$ BodipyFL proteasome activity probe for $5 \mathrm{~h}$. (a) Visualization of probe binding after SDS-PAGE using a 2D proteomic imaging system shows probe binding to the $\beta 2$ and $\beta 5$ subunits predominantly (activity). The lower panel is a western blot of the same samples showing that $\beta 2$ expression levels are not changed by the treatment (protein). (b) Quantification of the fluorescence intensity of the bands in the upper panel of (a), corrected for loading by the expression levels of eEF2 $\alpha$ (not shown) and presented as percent of untreated control (c) cells. This reflects the relative activity of the $\beta 2$ and $\beta 5$ subunits following $\mathrm{Tm}$ treatment
In addition, the earlier studies did not investigate the endogenous proteins, as in our study, in which we found a transcriptional response not affecting the protein levels.

Expression of the immunoproteasome in human brain increases with age. ${ }^{13}$ Inflammatory markers are increased in the elderly brain, providing support for an immune-mediated increase of the immunoproteasome. ${ }^{34}$ In the AD brain a myriad of immune responses can be observed associated with $\mathrm{A} \beta$ deposits, including activation of complement, increased levels of proinflammatory cytokines (e.g., IL-1 $\beta$, IL-6 and TNF- $\alpha$ ), activated glia and increased NF- $\kappa \mathrm{B}$ activation. $^{35,36}$

Our data showed intense $\beta 2 \mathrm{i}$ immunoreactivity in $A D$ pyramidal neurons, but less for $\beta 5 \mathrm{i}$, whereas both subunits were expressed in glial cells. The $\beta 5 \mathrm{i}$ subunit is encoded within the major histocompatibility class II locus. This locus is transcriptionally less active in neurons, possibly explaining the low $\beta 5$ i expression levels. Although ER stress is not involved 
a

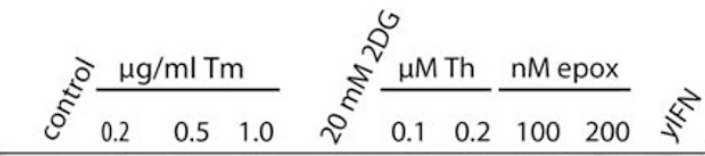

Ub
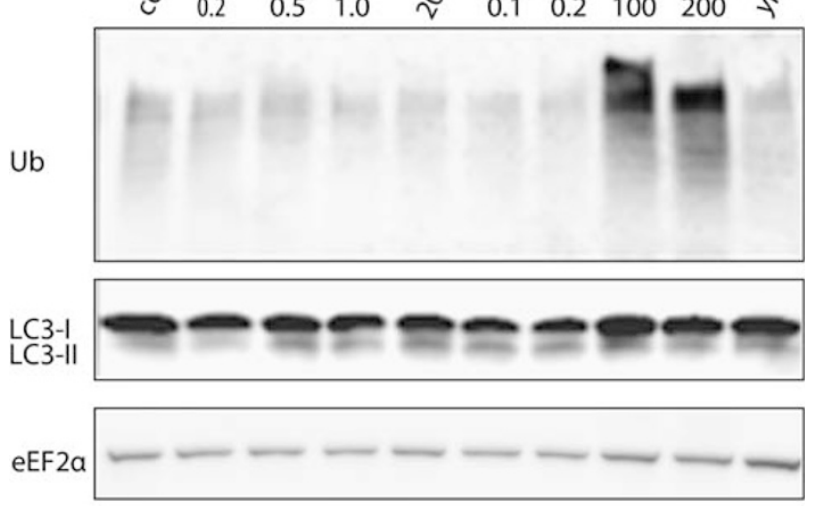

b

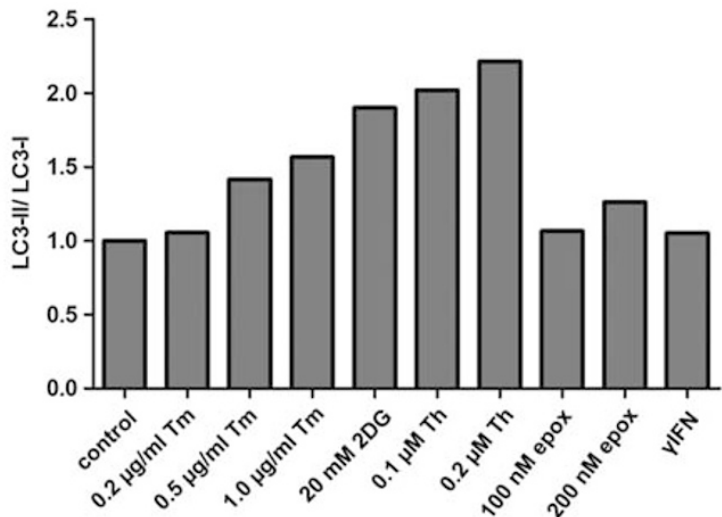

Figure 6 ER stress induces autophagy and does not lead to increased polyubiquitination. Differentiated SK-N-SH cells were treated with ER stressors (Tm, Th and 2DG), $\gamma \mathrm{IFN}$ and the proteasome inhibitor epoxomycin for $16 \mathrm{~h}$ and the protein levels were analyzed by western blotting. (a) Blots showing changes in the level of ubiquitinated $(\mathrm{Ub})$ proteins (upper panel) and LC3-I and LC3-II (middle panel) following treatment with ER stressors, $\gamma$ IFN and epoxomycin. The expression levels of eEF2 $\alpha$ are indicated as loading control. Blots from a representative experiment are shown. (b) LC3-II/LC3-I ratios determined from (a)

in increased expression of the immunoproteasome, this does not rule out a protective effect of the immunoproteasome when it is present. The immunoproteasome is capable of degrading tau more efficiently and with fewer intermediate fragments. ${ }^{9}$ Increased immunoproteasome levels may therefore attenuate tau aggregation.

Although total proteasome content is unchanged, decreased proteasome activity has been reported in AD. ${ }^{10,11}$ In contrast, a slight increase in activity was observed when proteasome complexes were purified. ${ }^{37}$ Aggregates like A $\beta$ can impair proteasome function in vitro ${ }^{38}$ and removal of these aggregates by proteasome purification might restore proteasome function. Using a direct assay to study proteasome activity, we demonstrated that UPR activation does not increase proteasome activity in our neuronal SK-N-SH cell model. A moderate decrease in proteasome activity, as measured by the accumulation of a fluorescently labelled UPS substrate, was previously described in MelJuso and Hela cell lines during chemically induced ER stress. ${ }^{26}$ As global translation is attenuated during ER stress, our activity probe assay gives a more direct and therefore more reliable result. We also observed a decrease in activity at higher ER stress levels. This may indicate that ER stress contributes to decreased proteasome activity in the AD brain. However, caution is warranted as under these conditions toxic side effects may obscure the data.

Combined, our experiments showed that, in contrast to the increased expression of ERAD components, UPR activation does not enhance proteasomal capacity in vitro. However, ER stress conditions are characterized by the accumulation of proteins in the ER, which need to be degraded in order to ensure cell survival. The observation that ubiquitinated proteins do not accumulate during ER stress suggests that efficient degradation is taking place. We have previously shown that inhibition of the proteasome does not induce a robust ER stress response, as would be expected if the UPS has an essential role in degrading these proteins. ${ }^{28}$ This appears to contradict studies showing that proteasome inhibition induces cancer cell apoptosis via ER stress. Dividing cells are dependent on the proteasome for cell cycle progression, and possibly this makes them more susceptible to proteasome inhibition than post-mitotic neuronal cells.

In agreement with other reports, ${ }^{15,16}$ we found that ER stress increases the LC3-II/LC3-I ratio, indicating that autophagy becomes more active. We demonstrated intense LC3 reactivity in pyramidal neurons in both $A D$ and nondemented controls, indicating an important role for autophagy in neurons in the human brain. This is in line with observations showing that levels of LC3-I and LC3-II are high in the mouse brain compared with other tissues. ${ }^{39}$ Disruption of autophagy causes the accumulation of polyubiquitinated proteins in neurons in mouse brain. ${ }^{18,19}$ The finding that ubiquitin is involved not only in targeting substrates to the UPS but also in selective autophagy supports this hypothesis.

High LC3 levels might be indicative of a highly active autophagy system and a priming of these cells to deal with misfolded proteins via autophagy. However, our antibody recognized both LC3-I and -II and thus did not give information about the autophagic state in brain. Alternatively, high LC3 levels might be indicative of a disturbed autophagic state, in which LC3 accumulates because it cannot be degraded. In addition to morphological observations of disturbed autophagy in $A D,{ }^{20}$ the levels of Beclin- 1 are decreased in $A D$ brain; ${ }^{40}$ therefore, different lines of evidence point to an impairment of autophagy in $A D$ neurons. Strikingly, we found high LC3 levels in neurons that show disturbed autophagy, demonstrated by the presence of GVD, and had activated the UPR. Our data indicate a direct link between UPR activation, autophagy and the occurrence of autophagic pathology in vivo.

If aberrant proteins accumulate to such extent that the UPR is induced, the ERAD process might be overwhelmed. In addition, higher amounts of misfolded proteins in the ER may more readily form aggregates, which cannot be exported. Under these conditions, bulk degradation of parts of the ER may be a more favorable pathway to restore homeostasis. This hypothesis is supported by the fact that ER stress markers are observed in GVD in AD and that these neurons display high levels of the autophagy marker LC3. It remains elusive whether autophagic pathology arises because the 

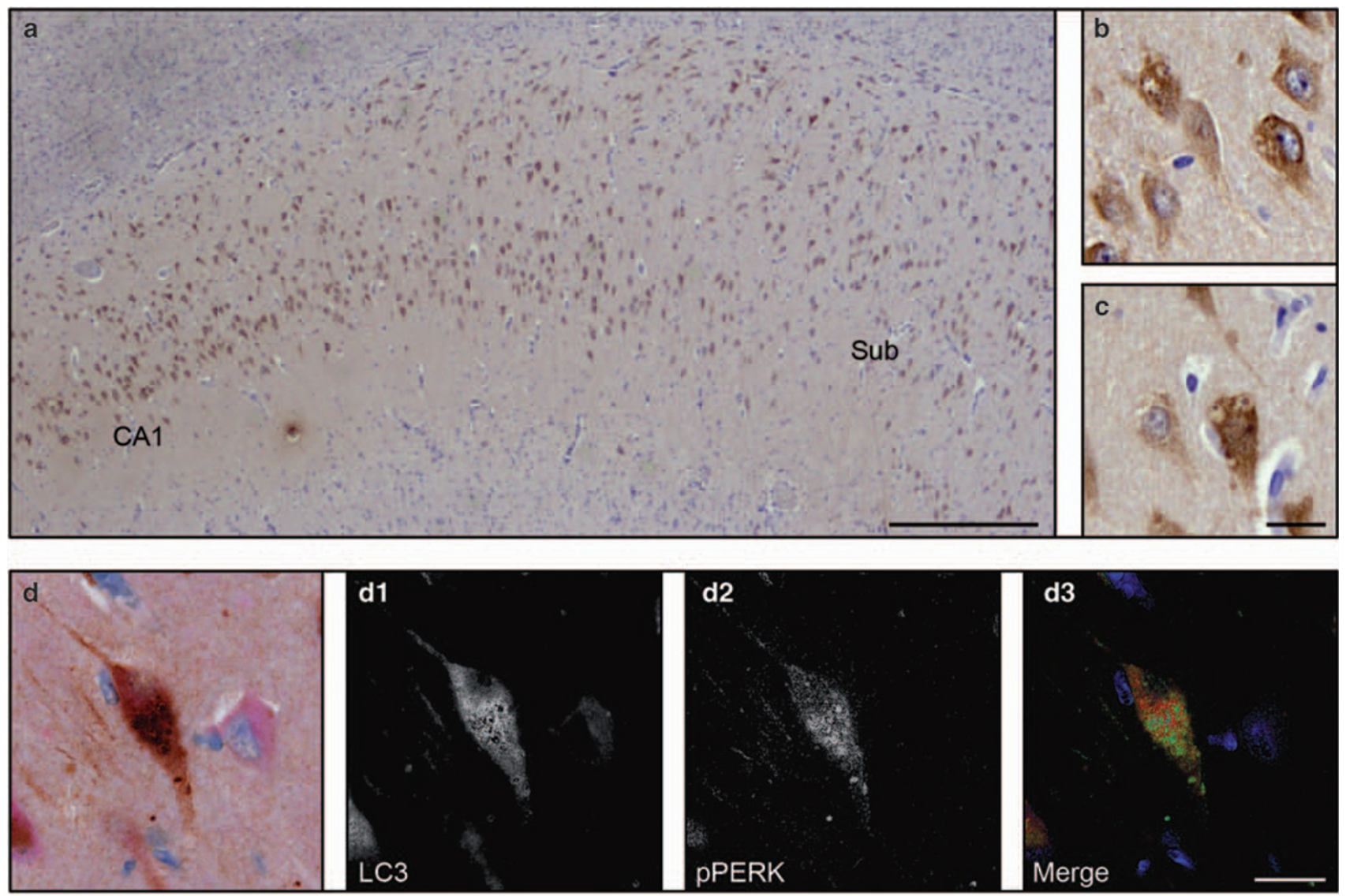

Figure 7 LC3 levels are increased in pPERK-positive neurons in the AD hippocampus. (a) Immunohistochemistry showing LC3 levels in hippocampal neurons of a representative $A D(B r a a k 4 C)$ case. A part of the CA1 and subiculum (sub) area is shown. Scale bar: $500 \mu \mathrm{M}$. (b and $\mathbf{c}$ ) Magnification of CA1 (b) and subiculum (c) from (a), showing LC3 levels are increased in neurons with GVD. (d) Representative double immunohistochemistry staining showing LC3 levels are increased in neurons that show pPERK reactivity. Nuclei were counterstained with hematoxylin (blue). The LC3 and pPERK signals were spectrally unmixed and are shown separately (d1 and d2, respectively) and as a merge with artificial colors (d3: LC3 red; pPERK green). Scale bar (b and c) $25 \mu \mathrm{M}$

autophagy system becomes overwhelmed or whether, with age for example, the autophagic system becomes less efficient.

Our data support a model in which the proteasome degrades misfolded proteins from the ER, but if this system is overloaded, autophagy is activated. This implies that autophagy is the major degradational pathway during activation of the UPR in neuronal cells. Figure 8 shows a diagram of all hypotheses tested in this study and the final model. As the UPR is activated in neurons in which tau is not aggregated into tangles, this pathway may provide a target for early therapeutic intervention in AD.

\section{Materials and Methods \\ Cell culture, differentiation and treatment. Human SK-N-SH neuroblastoma and HEK293 cells were cultured in Dulbecco's modified Eagle's medium with GlutaMAX (Gibco BRL, Carlsbad, CA, USA) supplemented with 10\% fetal calf serum (Gibco BRL) and $100 \mathrm{U} / \mathrm{ml}$ penicillin (Yamanouchi Pharma BV, Leiderdorp, The Netherlands). SK-N-SH cells were differentiated in culture medium supplemented with all trans-retinoic acid (Sigma, St Louis, MO, USA) in a final concentration of $10 \mu \mathrm{m}$ for 5 days. Differentiated cells were treated with $500 \mathrm{U} / \mathrm{ml}$ $\gamma$ IFN (PBL Biomedical Laboratories, Piscataway, NJ, USA), epoxomycin, Tm, Th and 2DG (all from Sigma, USA) at the indicated concentrations for $16 \mathrm{~h}$.}

RNA isolation and cDNA synthesis. For RNA isolation, differentiated SK-N-SH cells $\left(5 \times 10^{5}\right.$ per well in a six-well plate) were harvested in TRlzol reagent
(Invitrogen, Carlsbad, CA, USA) and total RNA was isolated using the QIAcube (QIAGEN, Venlo, The Netherlands). The protocol was used according to the manufacturer's specifications. RNA concentrations and purity were assessed by OD measurements at 260 and $280 \mathrm{~nm}$ on a NanoDrop spectrophotometer (Thermo Scientific, Waltham, MA, USA). For cDNA synthesis, $1 \mu \mathrm{g}$ of RNA and $125 \mathrm{pmol}$ OligodT12 primer were dissolved in a total of $10 \mu \mathrm{H}_{2} \mathrm{O}$ and incubated at $72^{\circ} \mathrm{C}$ for $10 \mathrm{~min}$. Reverse transcriptase mix was added, consisting of $5 \mu \mathrm{l} 5 \times$ first-strand buffer (Invitrogen), $0.5 \mu \mathrm{l}$ SuperScript II RNA polymerase (Invitrogen), $10 \mathrm{mM} d N T P s$ and $25 \mathrm{mM} \mathrm{MgCl}_{2}$ in a total of $15 \mu \mathrm{l} \mathrm{H}_{2} \mathrm{O}$. The mixture was incubated at $42^{\circ} \mathrm{C}$ for $1 \mathrm{~h}$, followed by $15 \mathrm{~min}$ at $70^{\circ} \mathrm{C}$. CDNA quality was assessed on $0.8 \%$ agarose gel.

Real-time qPCR. Real-time qPCR was performed using the Light Cycler 480 system (Roche Applied Science, Indianapolis, IN, USA). Oligonucleotide primers (Sigma, USA) used for qPCR are listed in Table 1. Reaction volumes of $5 \mu \mathrm{l}$ contained cDNA, $0.1 \mu \mathrm{M}$ Universal Probe Library probe (Roche Applied Science), also listed in Table 1, $0.4 \mu \mathrm{M}$ forward primer, $0.4 \mu \mathrm{M}$ reverse primer and $2.5 \mu \mathrm{l} 2 \times$ LightCycler 480 Probes Master (Roche Applied Science). After denaturation for $10 \mathrm{~min}$ at $95^{\circ} \mathrm{C}$, amplification was performed using 35 cycles of denaturation $\left(95^{\circ} \mathrm{C}\right.$ for $10 \mathrm{~s})$, followed by annealing $\left(58^{\circ} \mathrm{C}\right.$ for $\left.15 \mathrm{~s}\right)$ and elongation $\left(72^{\circ} \mathrm{C}\right.$ for $\left.15 \mathrm{~s}\right)$. Results were analyzed using the LightCycler 480 software (Roche Applied Science) version 1.5 .

Western blotting. To obtain lysates, differentiated SK-N-SH cells $\left(2 \times 10^{5}\right.$ per well in a 12-well plate) were scraped in ice-cold lysis buffer containing $1 \%$ Triton X-100 and protease inhibitor cocktail (Roche Applied Science) in PBS. The lysate (supernatant) was obtained after centrifugation at $12000 \times g$ at $4^{\circ} \mathrm{C}$ for $8 \mathrm{~min}$. Protein concentration was determined with a Bradford protein assay (Bio-Rad 
a

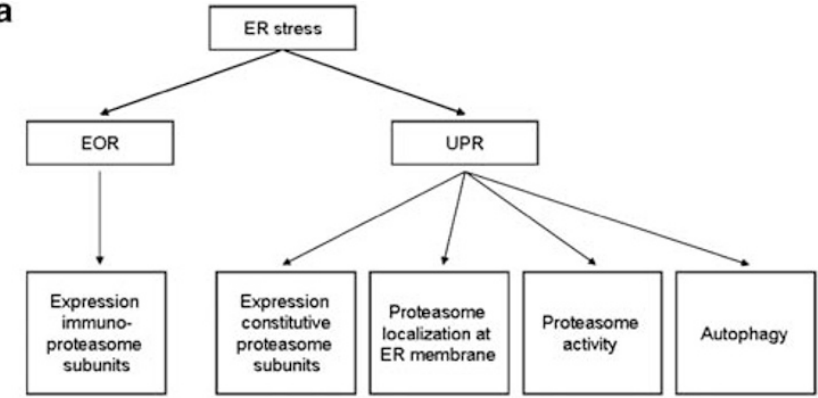

b Physiological

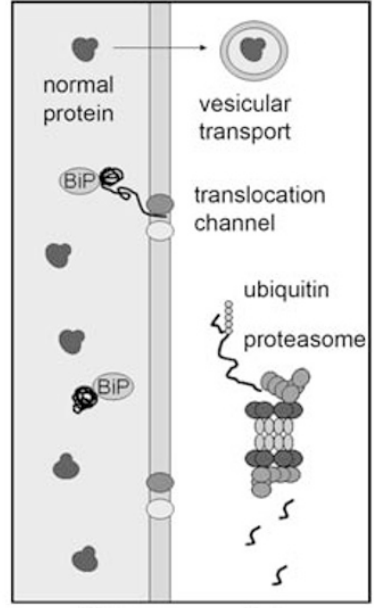

ER

cytoplasm

UPR

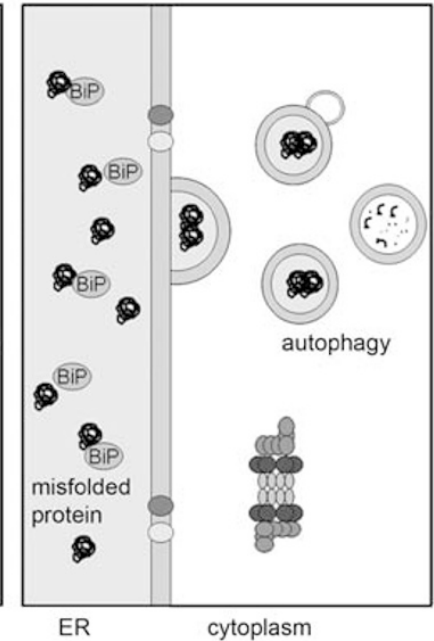

Figure 8 ER stress preferentially activates autophagy in neuronal cells. (a) Diagram showing the pathways investigated in this study by which ER stress may increase the proteolytic capacity of neuronal cells. ER stress could enhance proteolytic degradation by the proteasome by influencing the subunit composition via activation of the EOR. Alternatively, the UPR can be employed to enhance the expression levels of the constitutive subunits. In addition, regulation of the localization or activity of the proteasome may occur. In addition, the UPR may result in activation of autophagy. (b) Our data show that a disturbance of ER homeostasis resulting in activation of the UPR will activate the autophagy pathway. This can be due to a decreased capability to export misfolded proteins from the ER lumen under these conditions or may relate to the inability of the proteasome to degrade aggregated proteins. In AD neurons, decreased proteasomal degradation as well as a disruption in the autophagosomal/lysosomal system may eventually lead to neurodegeneration

Laboratories, Veenendaal, The Netherlands). Equal amounts of protein were analyzed on $8 \%$ (BiP, eEF2 $\alpha$ ), $10 \%$ (ubiquitin) $12 \%$ ( $\beta 2, \beta 2 \mathrm{i}, \beta 5 \mathrm{i}$ ) or $18 \%$ (LC3) SDS-PAGE gels and blotted onto PVDF membrane (Millipore, Billerica, MA, USA) using a semi-dry electro blotting apparatus. Blots were pre-incubated with $5 \%$ nonfat dried milk in PBS-T (0.05\% Tween-20 in PBS) for $1 \mathrm{~h}$ and subsequently incubated at $4^{\circ} \mathrm{C}$ for $16 \mathrm{~h}$ with primary antibodies. Membranes were washed $3 \times 10 \mathrm{~min}$ in PBS-T and subsequently incubated with species-specific secondary antibodies conjugated to horseradish peroxidase (dilution 1:2000, Dako, Glostrup, Denmark). Reactive protein bands were visualized using LumiLightPLUS Western blotting substrate (Roche Applied Science) and a LAS-3000 luminescent image analyzer (Fuji Photo Film (Europe), Kleve, Germany). Results were analyzed using Advanced Image Data Analyzer software (Raytest, Straubenhardt, Germany) version 3.44.035. The primary antibodies and their dilution factors that were used in this study are listed in Table 2.

Construction of plasmids. The promoter region $500 \mathrm{bp}$ upstream of the transcription start site of the human $\beta 2$ i gene was amplified from human genomic DNA. The promoter sequence was derived from the genomic sequence database at http://www.ensembl.org (NM 002801). Nested PCR was used to maximize the chances of obtaining the correct fragment. The first round of amplification was performed using the primers described in Table 3. A thermocycler was used to amplify the DNA templates. Reaction volumes of $50 \mu$ l contained $1 \times$ PCR buffer (Stratagene, Santa Clara, CA, USA), $1 \mathrm{mM}$ dNTPs, $2 \mathrm{mM} \mathrm{MgCl}_{2}, 0.25 \mu \mathrm{M}$ reverse primer, $0.25 \mu \mathrm{M}$ forward primer, $0.05 \mathrm{U} / \mu \mathrm{l}$ HotFire Taq polymerase (Stratagene) and $20 \mu \mathrm{g}$ human genomic DNA. The thermocycler protocol consisted of a 5-min denaturation step at $95^{\circ} \mathrm{C}$; amplification was performed using 35 cycles of denaturation $\left(95^{\circ} \mathrm{C}\right.$ for $\left.45 \mathrm{~s}\right)$, annealing $\left(55^{\circ} \mathrm{C}\right.$ for $\left.1 \mathrm{~min}\right)$ and elongation $\left(72^{\circ} \mathrm{C}\right.$ for $1 \mathrm{~min}$ ). The final extension was performed at $72^{\circ} \mathrm{C}$ for $8 \mathrm{~min}$. The nested primers used were extended with an Xhol or Hindlll endonuclease site (Table 3). PCR reactions were performed as described above, with the exception of a 1-min denaturing step, in a total reaction volume of $50 \mu \mathrm{l}$. The PCR product size was analyzed by agarose gel electrophoresis, sequenced and purified using the High Pure PCR Cleanup Micro Kit (Roche Applied Science). The $\beta 2$ i promoter fragment was digested using the restriction enzymes Xhol and Hindlll and subsequently ligated into the pGL3-basic luciferase reporter vector (Promega, Madison, WI, USA). The $\beta 2 \mathrm{i}$ promoter NF- $\kappa \mathrm{B}$-binding site was abolished by site-directed mutagenesis using the QuickChange Site Directed Mutagenesis kit (Stratagene), according to the manufacturer's protocol. Three guanines, located in the NF- $\kappa$ B consensus site, were substituted by thymidines, rendering the site non-functional. The BiP promoter construct used was previously described. ${ }^{22}$

Promoter activity assay. For transient transfections, HEK 293 cells $\left(10^{5}\right.$ cells per well in a 24-well plate) were transfected using Lipofectamine 2000 (Invitrogen) according to the manufacturer's protocol. One hundred nanograms of DNA of luciferase reporter construct was cotransfected with $1 \mathrm{ng}$ CMV-Renilla construct (Promega). Cells were incubated for $16 \mathrm{~h}$ and treated with different concentrations of TM and $\gamma \mathrm{IFN}$ for an additional $16 \mathrm{~h}$. Cells were harvested by scraping into $250 \mu \mathrm{l}$ Passive Lysis Buffer (Promega), vigorous shaking for $15 \mathrm{~min}$ and $12000 \times g$ centrifugation at $4^{\circ} \mathrm{C}$ for $8 \mathrm{~min}$. The sample $(20 \mu \mathrm{l})$ was incubated with a Renilla or Luciferase substrate (Promega) and luminescence was measured on a GloMax Multi Microplate Multimode Reader (Promega).

Immunocytochemistry. Differentiated SK-N-SH cells were grown $\left(2 \times 10^{5}\right.$ cells per well in a 12-well plate) on non-coated sterile glass coverslips. Cells were washed in ice-cold PBS and fixed using 4\% paraformaldehyde (Sigma, Zwijndrecht, The Netherlands) for $15 \mathrm{~min}$ and permeabilized in ice-cold $\left(-20^{\circ} \mathrm{C}\right)$ methanol (Merck, Darmstadt, Germany) for 5 min. To block antibody non-specific binding, the cells were incubated in blocking buffer $(0.1 \%$ bovine serum albumin (BSA; Boehringer, Mannheim, Germany) and 0.05\% saponine (in PBS-T, Sigma, The Netherlands)) for $30 \mathrm{~min}$ at room temperature. Double staining was performed using antibodies directed against $\beta 5 i$ and calnexin in blocking buffer at room temperature for $1 \mathrm{~h}$ (Table 2). Glass slides were washed in PBS-T and subsequently incubated with species-specific secondary antibodies labelled with Cy3 or FITC fluorescent label (dilution 1:200 in blocking buffer, Jackson Immuno Research, Westgrove, PA, USA) for $1 \mathrm{~h}$. Cells were washed in PBS-T and incubated with diamidino phenylindole (DAPI, dilution $1: 1000$, Sigma, USA) for 5 min. After rinsing in PBS the glass slides were air dried, embedded in vectashield (Vector Laboratories, Burlingame, CA, USA) and mounted onto glass slides. Imaging was performed using a Leica TCS-SP mounted on an inverted microscope (Leica, Solms, Germany) equipped with a digital CCD camera.

In-gel proteasome activity assay. SK-N-SH cells $\left(10^{5}\right.$ cells per well in a 24-well plate) were differentiated for 7 days before incubation for $16 \mathrm{~h}$ in the presence or absence of $\mathrm{Tm}$ before addition of $\mathrm{Me}_{4}$ BodipyFL-Ahx ${ }_{3} \mathrm{LeU}_{3} \mathrm{VS}$ $\left(\mathrm{Me}_{4}\right.$ BodipyFL probe), a close analog of the BodipyFL probe described previously, ${ }^{27}$ at a concentration of $500 \mathrm{nM}$ for $5 \mathrm{~h}$, followed by a chase for $1 \mathrm{~h}$ with MG132. The in-gel proteasome activity assay was performed essentially as described. ${ }^{27}$ In short, cells were lysed in ice-cold lysis buffer and equal amounts of protein were separated on a $12.5 \%$ SDS-PAGE gel. In-gel visualization of the labelled subunits was performed in the wet gel slabs directly by using the GFP settings $\left(\lambda_{\mathrm{ex}} 480, \lambda_{\mathrm{em}} 510\right)$ on the Typhoon Variable Mode Imager (Amersham Biosciences, Diegem, Belgium).

Immunohistochemistry. Post-mortem brain material was obtained from the Netherlands Brain Bank (Table 4). Informed consent is available for each patient. Sections ( $5 \mu \mathrm{m}$ thick) were mounted onto Superfrost plus tissue slides (MenzelGläser, Braunschweig, Germany) and dried overnight at $37^{\circ} \mathrm{C}$. For all stainings 
sections were deparaffinized and subsequently immersed in $0.3 \% \mathrm{H}_{2} \mathrm{O}_{2}$ in methanol for $30 \mathrm{~min}$ to quench endogenous peroxidase activity and washed for $5 \mathrm{~min}$ in PBS. Sections were treated with $10 \mathrm{mmol} / \mathrm{l}, \mathrm{pH} 6.0$, sodium citrate buffer heated by microwave for $10 \mathrm{~min}$ for antigen retrieval and subsequently incubated with primary antibodies at $4^{\circ} \mathrm{C}$ for $16 \mathrm{~h}$. Antibodies (Table 2) were diluted in PBS containing $1 \%$ (w/v) BSA (Boehringer). Negative controls for all immunostainings were generated by omission of primary antibodies. Sections were washed $3 \times 10$ min with PBS and subsequently incubated with horseradish peroxidase-labelled $\alpha$ mouse/rabbit secondary antibody (Dako REAL EnVision/HRP Rabbit/Mouse, Dako, Hamburg, Germany). Color was developed using 3,3'-diaminobenzidine $(0.1 \mathrm{mg} / \mathrm{ml}, 0.02 \%$ $\mathrm{H}_{2} \mathrm{O}_{2}, 10$ min; Sigma, USA) as chromogen. Sections were counterstained with hematoxylin and mounted using Depex (BDH Laboratories Supplies, East Grinstead, UK). For double immunohistochemistry with pPERK and LC3, sections were treated as described above to quench endogenous peroxidase

Table 1 Primers and probes used for qPCR 480 light cycler

\begin{tabular}{|c|c|c|c|}
\hline Gene & Primers $\left(5^{\prime}-3^{\prime}\right)$ & $\begin{array}{l}\text { Product } \\
\text { size (bp) }\end{array}$ & $\begin{array}{l}\text { Probe } \\
\text { no. }\end{array}$ \\
\hline HC5 (PSMB1) & $\begin{array}{l}\text { FW: gggtcttaccagagagactcctt } \\
\text { RV: gctccacattctgcatgttc }\end{array}$ & 105 & 19 \\
\hline C7 (PSMB2) & $\begin{array}{l}\text { FW: cctcgaccgatactacacacc } \\
\text { RV: caggatgaagcgtttctgg }\end{array}$ & 73 & 25 \\
\hline$\beta 1$ (PSMB6) & $\begin{array}{l}\text { FW: ggcggctaccttactagctg } \\
\text { RV: aaactgcacggccatgata }\end{array}$ & 124 & 48 \\
\hline$\beta 2$ (PSMB7) & $\begin{array}{l}\text { FW: tgataagttgccttatgtcacca } \\
\text { RV: ggcctaaacttatcttcaaatacagc }\end{array}$ & 75 & 36 \\
\hline$\beta 5$ (PSMB5) & $\begin{array}{l}\text { FW: catgatctgtggctgggata } \\
\text { RV: ttcccttcactgtccacgta }\end{array}$ & 60 & 81 \\
\hline$\beta 1 \mathrm{i}$ (PSMB9) & $\begin{array}{l}\mathrm{FW} \text { : tcccaggttggaaaccagt } \\
\mathrm{RV} \text { : tcaaactccactgccatgat }\end{array}$ & 140 & 89 \\
\hline$\beta 2 \mathrm{i}(\mathrm{PSMB} 10)$ & $\begin{array}{l}\text { FW: ggttccagccgaacatga } \\
\text { RV: gcccaggtcacccaagat }\end{array}$ & 83 & 31 \\
\hline $\begin{array}{l}\beta 5 \text { i variant } 1 \\
\text { (PSMB8.1) }\end{array}$ & $\begin{array}{l}\text { FW: ccctacccacccctgttt } \\
\text { RV: cacccagggactggaaga }\end{array}$ & 69 & 1 \\
\hline $\begin{array}{l}\beta 5 \text { i variant } 2 \\
\text { (PSMB8.2) }\end{array}$ & $\begin{array}{l}\text { FW: gttccagcatggagtgattg } \\
\text { RV: tggttcacccgtaaggcact }\end{array}$ & 77 & 86 \\
\hline $\mathrm{BiP}$ & $\begin{array}{l}\text { FW: catcaagttcttgccgttca } \\
\text { RV: tcttcaggagcaaatgtctttgt }\end{array}$ & 99 & 10 \\
\hline CHOP/Gadd153 & $\begin{array}{l}\text { RV: aaggcactgagcgtatcat } \\
\text { FW: tgaagatacacttccttcttgaaca }\end{array}$ & 105 & 21 \\
\hline GAPDH & $\begin{array}{l}\text { FW: gctgagtccgcagcagg } \\
\text { RV: tgccaacagggagagcaga }\end{array}$ & 78 & 45 \\
\hline
\end{tabular}

Probe numbers refer to numbers in the Roche universal probe library activity and incubated with the PPERK antibody diluted in PBS containing 1\% BSA at room temperature for $1 \mathrm{~h}$. Sections were washed $3 \times 10 \mathrm{~min}$ with PBS and subsequently incubated with horseradish-labelled goat-anti-rabbit secondary antibody (Dako, Germany) for $1 \mathrm{~h}$. Sections were washed $3 \times 10$ min with PBS and color was developed using $3,3^{\prime}$-diaminobenzidine $\left(0.1 \mathrm{mg} / \mathrm{ml}, 0.02 \% \mathrm{H}_{2} \mathrm{O}_{2}\right.$, $10 \mathrm{~min}$; Sigma, USA) as chromogen. Development time was determined using a single antibody control. Sections were washed with water and subsequently treated with $10 \mathrm{mmol} / \mathrm{l} \mathrm{pH} 6.0$ sodium citrate buffer heated by autoclave for $10 \mathrm{~min}$ for antigen retrieval. Sections were washed with PBS for $5 \mathrm{~min}$, pre-incubated with normal swine serum (1:10 in 5\% BSA/PBS, Dako, Germany) for $10 \mathrm{~min}$ and incubated with the LC3 antibody at $4{ }^{\circ} \mathrm{C}$ for $16 \mathrm{~h}$. Sections were washed $3 \times 10 \mathrm{~min}$ with PBS and incubated with biotinylated swine-anti-rabbit $(1: 300$ in $5 \%$ BSA/PBS, Dako, Germany) for $1 \mathrm{~h}$. Sections were washed $3 \times 10 \mathrm{~min}$ with PBS and incubated with streptavidin horseradish peroxidase (1:100 in 5\% BSA/PBS, Dako, Germany) for $1 \mathrm{~h}$. Sections were washed $3 \times 10$ min with PBS and $1 \times$ in Tris-HCl buffer (pH 6.8). Color was developed using liquid permanent red (LPR, Dako, Germany). Development time was determined using a single antibody control. Sections were counterstained with hematoxylin and mounted using Aquamount (BDH Laboratories Supplies). A section incubated only with pPERK antibody but developed at the LPR step was used as a cross-reactivity control. Double immunohistochemistry using $\beta 5 \mathrm{i}$ and GFAP or Iba was performed as described above with minor modifications. Slides were pre-incubated with normal goat serum (1:10 in 5\% BSA/PBS) and incubated with both primary antibodies overnight at $4{ }^{\circ} \mathrm{C}$. Sections were washed $3 \times 10$ min with PBS and subsequently incubated with horseradish-labelled goatanti-mouse (undiluted, Dako, Germany) and biotinylated goat-anti-rabbit (1:100 in $5 \%$ BSA/PBS, Dako, Germany) antibodies. Slides were washed $3 \times 10$ min in PBS

Table 3 Primers used for subcloning of the $\beta 2$ i promoter

\begin{tabular}{cc}
\hline \multicolumn{2}{c}{$\beta 2 i$ first-round primers } \\
FW & $5^{\prime}$-TTTAGAAAGACCCGCTCT-3' \\
RV & $5^{\prime}$-GCTAGGCTTCACGTCTGT-3'
\end{tabular}

Nested primers with endonuclease site

$\begin{array}{ll}\text { FW-Xhol } & 5^{\prime} \text {-ATACTCGAGTGGTGCCCTCTTGAGAGA-3' } \\ \text { RV-HindlII } & 5^{\prime} \text {-CGCAAGCTTGTACTTCCTGCTTTCGCT-3' }\end{array}$

Site-directed mutagenesis primers

FW 5'-AGCACAGAGGGCACAGCAATTTACATCACCC

GGTTCCC-3'

5'-GGGAACCGGGTGATGTAAATTGCTGTG CCCTCTGTGCT-3

Endonuclease sites are in italics. Mutated nucleotides are indicated in bold

Table 2 Primary antibodies and their sources and use

\begin{tabular}{|c|c|c|c|c|}
\hline Antibody & Species & Mono/polyclonal & Dilution & Company \\
\hline \multicolumn{5}{|c|}{ Antibodies for western blot analysis } \\
\hline $\mathrm{BiP} / \mathrm{GRP} 78$ & Goat & Polyclonal & $1: 1000$ in $2.5 \%$ milk/PBS-T & Santa-Cruz, USA \\
\hline$\beta 2$ & Mouse & Polyclonal & $1: 500$ in $5 \%$ BSA/PBS-T & Abnova, Taiwan \\
\hline$\beta 2 \mathrm{i}$ & Mouse & Monoclonal & $1: 500$ in $5 \%$ BSA/PBS-T & Abnova, Taiwan \\
\hline$\beta 5 \mathrm{i}$ & Mouse & Monoclonal & $1: 500$ in $5 \%$ BSA/PBS-T & Abnova, Taiwan \\
\hline LC3 & Rabbit & Polyclonal & $1: 1000$ in $2.5 \%$ milk/PBS-T & Novus Biologicals, USA \\
\hline Ubiquitin & Mouse & Monoclonal & $1: 1000$ in $2.5 \%$ milk/PBS-T & Chemicon, USA \\
\hline $\mathrm{eEF} 2 \alpha$ & Rabbit & Polyclonal & $1: 1000$ in $2.5 \%$ milk/PBS-T & Cell Signal, USA \\
\hline \multicolumn{5}{|c|}{ Antibodies for immunocytochemistry } \\
\hline$\beta 5 i$ & Mouse & Monoclonal & $1: 200$ in $1 \%$ BSA/0.05\% saponin/PBS-T & Abnova, Taiwan \\
\hline Calnexin & Rabbit & Polyclonal & $1: 200$ in $1 \%$ BSA/0.05\% saponin/PBS-T & Calbiochem/Merck, Germany \\
\hline \multicolumn{5}{|c|}{ Antibodies for immunohistochemistry } \\
\hline$\beta 2 \mathrm{i}$ & Mouse & Monoclonal & $1: 100$ in $5 \%$ BSA/PBS-T & Abnova, Taiwan \\
\hline$\beta 5 i$ & Mouse & Monoclonal & $1: 200$ in $5 \%$ BSA/PBS-T & Abnova, Taiwan \\
\hline pPERK (Thr980) & Rabbit & Monoclonal & $1: 1000$ in $5 \%$ BSA/PBS-T & Santa Cruz, USA \\
\hline LC3 & Rabbit & Polyclonal & $\begin{array}{l}1: 25600 \text { in } 5 \% \text { BSA/PBS-T or } 1: \\
10000 \text { for double immunohistochemistry }\end{array}$ & Novus Biologicals, USA \\
\hline Iba1 & Rabbit & Polyclonal & $1: 6400$ in $5 \%$ BSA/PBS-T & Wako, USA \\
\hline GFAP & Rabbit & Polyclonal & $1: 1800$ in $5 \%$ BSA/PBS-T & Dako, Denmark \\
\hline
\end{tabular}


Table 4 Overview of the post-mortem brain material used in this study

\begin{tabular}{lccccccc}
\hline Case & $\begin{array}{c}\text { Braak score } \\
\text { for NFT }\end{array}$ & $\begin{array}{c}\text { Braak score } \\
\text { for amyloid }\end{array}$ & $\begin{array}{c}\text { Clinical } \\
\text { diagnosis }\end{array}$ & Age & Sex & $\begin{array}{c}\text { PMI } \\
\text { (h) }\end{array}$ \\
\hline 1 & 0 & 0 & CON & 57 & M & 6 \\
2 & 0 & A & CON & 66 & F & 5 \\
3 & 1 & A & CON & 82 & F & 5 \\
4 & 2 & 0 & CON & 78 & M & 6 \\
5 & 3 & C & MCl & 74 & M & 5 \\
6 & 3 & C & AD & 69 & F & 5 \\
7 & 4 & C & AD & 57 & F & 5 \\
8 & 5 & C & AD & 87 & M & 6 \\
9 & 6 & C & AD & 57 & M & 5 \\
10 & 6 & C & AD & 80 & F & 6 \\
\hline
\end{tabular}

Abbreviations: $\mathrm{CON}$, control case; $\mathrm{F}$, female; $\mathrm{M}$, male; $\mathrm{MCl}$, mild cognitive impairment; PMI, post-mortem interval

and incubated with streptavidin horseradish peroxidase (1:100 in 5\% BSA/PBS, Dako, Germany) for $1 \mathrm{~h}$. Sections were washed $3 \times 10 \mathrm{~min}$ in PBS and developed using $3,3^{\prime}$-diaminobenzidine as chromogen. Slides were washed in water and in $1 \times$ Tris-HCl buffer before developing with LPR. Sections were counterstained with hematoxylin and mounted using Aquamount. We used the Nuance spectral imaging system (CRi, Woburn, MA, USA) to analyze the double-stained sections. Spectral libraries of single-brown (DAB), single-red (LPR) and hematoxylin were obtained from control sections. The spectral library was used to unmix the different reactions products in the double-stained sections into black and white images. These images represent the localization of each of the reaction products and were reverted to fluorescence-like images composed of pseudo-colors by the Nuance software.

\section{Conflict of interest}

The authors declare no conflict of interest.

Acknowledgements. Human brain tissue was supplied by the Netherlands Brain Bank. This study was supported by Internationale Stichting Alzheimer Onderzoek Nederland (ISAO \#07506) and the Netherlands Organisation for Scientific Research (NWO). We thank Lisette Schmidt for initial experiments and Line De Kimpe and Hyung Elfrink for stimulating discussions.

1. Braak H, Braak E. Staging of Alzheimer's disease-related neurofibrillary changes Neurobiol Aging 1995; 16: 271-278.

2. Hoozemans JJM, van Haastert ES, Nijholt DAT, Rozemuller AJM, Eikelenboom $P$ Scheper W. The unfolded protein response is activated in pretangle neurons in Alzheimer's disease hippocampus. Am J Pathol 2009; 174: 1241-1251.

3. Hoozemans JJM, Veerhuis R, van Haastert ES, Rozemuller JM, Baas F, Eikelenboorn P et al. The unfolded protein response is activated in Alzheimer's disease. Acta Neuropathol 2005; 110: 165-172.

4. Meyer M, Caselmann WH, Schluter V, Schreck R, Hofschneider PH, Baeuerle PA Hepatitis B virus transactivator MHBst: activation of NF-kappa B, selective inhibition by antioxidants and integral membrane localization. EMBO J 1992; 11: 2991-3001.

5. Pahl HL, Baeuerle PA. A novel signal transduction pathway from the endoplasmic reticulum to the nucleus is mediated by transcription factor NF-kappa B. EMBO J 1995; 14 2580-2588.

6. Hoseki J, Ushioda R, Nagata K. Mechanism and components of endoplasmic reticulumassociated degradation. J Biochem 2010; 147: 19-25.

7. Yoshida H, Matsui T, Hosokawa N, Kaufman RJ, Nagata K, Mori K. A time-dependent phase shift in the mammalian unfolded protein response. Dev Cell 2003; 4: 265-271.

8. Pickart CM, Cohen RE. Proteasomes and their kin: proteases in the machine age. Nat Rev Mol Cell Biol 2004; 5: 177-187.

9. Cardozo C, Michaud C. Proteasome-mediated degradation of tau proteins occurs independently of the chymotrypsin-like activity by a nonprocessive pathway. Arch Biochem Biophys 2002; 408: 103-110.

10. Cecarini V, Ding Q, Keller JN. Oxidative inactivation of the proteasome in Alzheimer's disease. Free Radic Res 2007; 41: 673-680.

11. Keller JN, Hanni KB, Markesbery WR. Impaired proteasome function in Alzheimer's disease. J Neurochem 2000; 75 : 436-439.
12. McNaught KS, Bjorklund LM, Belizaire R, Isacson O, Jenner P, Olanow CW. Proteasome inhibition causes nigral degeneration with inclusion bodies in rats. NeuroReport 2002; 13: 1437-1441.

13. Mishto M, Bellavista E, Santoro A, Stolzing A, Ligorio C, Nacmias B et al. Immunoproteasome and LMP2 polymorphism in aged and Alzheimer's disease brains. Neurobiol Aging 2006; 27: 54-66.

14. Drews $\mathrm{O}$, Wildgruber R, Zong $\mathrm{C}$, Sukop U, Nissum M, Weber G et al. Mammalian proteasome subpopulations with distinct molecular compositions and proteolytic activities. Mol Cell Proteomics 2007; 6: 2021-2031.

15. Yorimitsu T, Nair U, Yang Z, Klionsky DJ. Endoplasmic reticulum stress triggers autophagy. J Biol Chem 2006; 281: 30299-30304.

16. Ogata M, Hino S, Saito A, Morikawa K, Kondo S, Kanemoto S et al. Autophagy is activated for cell survival after endoplasmic reticulum stress. Mol Cell Biol 2006; 26: 9220-9231.

17. Ding WX, Ni HM, Gao W, Yoshimori T, Stolz DB, Ron D et al. Linking of autophagy to ubiquitin-proteasome system is important for the regulation of endoplasmic reticulum stress and cell viability. Am J Pathol 2007; 171: 513-524.

18. Hara T, Nakamura K, Matsui M, Yamamoto A, Nakahara Y, Suzuki-Migishima R et al. Suppression of basal autophagy in neural cells causes neurodegenerative disease in mice. Nature 2006; 441: 885-889.

19. Komatsu M, Waguri S, Chiba T, Murata S, Iwata J, Tanida I et al. Loss of autophagy in the central nervous system causes neurodegeneration in mice. Nature 2006; 441: 880-884.

20. Boland B, Kumar A, Lee S, Platt FM, Wegiel J, Yu WH et al. Autophagy induction and autophagosome clearance in neurons: relationship to autophagic pathology in Alzheimer's disease. J Neurosci 2008; 28: 6926-6937.

21. Okamoto K, Hirai S, lizuka T, Yanagisawa T, Watanabe M. Reexamination of granulovacuolar degeneration. Acta Neuropathol 1991; 82: 340-345.

22. Kap YS, Hoozemans JJ, Bodewes AJ, Zwart R, Meijer OC, Baas F et al. Pin1 levels are downregulated during ER stress in human neuroblastoma cells. Neurogenetics 2007; 8: 21-27

23. Brooks P, Murray RZ, Mason GG, Hendil KB, Rivett AJ. Association of immunoproteasomes with the endoplasmic reticulum. Biochem J 2000; 352(Part 3): 611-615.

24. Palmer A, Rivett AJ, Thomson S, Hendil KB, Butcher GW, Fuertes G et al. Subpopulations of proteasomes in rat liver nuclei, microsomes and cytosol. Biochem J 1996; 316(Part 2): 401-407.

25. Reits EA, Benham AM, Plougastel B, Neefjes J, Trowsdale J. Dynamics of proteasome distribution in living cells. EMBO J 1997; 16: 6087-6094.

26. Menendez-Benito V, Verhoef LG, Masucci MG, Dantuma NP. Endoplasmic reticulum stress compromises the ubiquitin-proteasome system. Hum Mol Genet 2005; 14: 2787-2799.

27. Verdoes M, Florea BI, Menendez-Benito V, Maynard CJ, Witte MD, van der Linden WA et al. A fluorescent broad-spectrum proteasome inhibitor for labeling proteasomes in vitro and in vivo. Chem Biol 2006; 13: 1217-1226.

28. Chafekar SM, Hoozemans JJ, Zwart R, Baas F, Scheper W. Abeta 1-42 induces mild endoplasmic reticulum stress in an aggregation state-dependent manner. Antioxid Redox Signal 2007; 9: 2245-2254.

29. Yorimitsu T, Klionsky DJ. Endoplasmic reticulum stress: a new pathway to induce autophagy. Autophagy 2007; 3: 160-162.

30. Mizushima N, Yoshimori T. How to interpret LC3 immunoblotting. Autophagy 2007; 3: 542-545.

31. Diaz-Hernandez M, Hernandez F, Martin-Aparicio E, Gomez-Ramos P, Moran MA, Castano JG et al. Neuronal induction of the immunoproteasome in Huntington's disease. J Neurosci 2003; 23: 11653-11661.

32. Puttaparthi K, Elliott JL. Non-neuronal induction of immunoproteasome subunits in an ALS model: possible mediation by cytokines. Exp Neurol 2005; 196: 441-451.

33. Diaz-Hernandez M, Martin-Aparicio E, Avila J, Hernandez F, Lucas JJ. Enhanced induction of the immunoproteasome by interferon gamma in neurons expressing mutant Huntingtin. Neurotox Res 2004; 6: 463-468.

34. Godbout JP, Johnson RW. Interleukin-6 in the aging brain. J Neuroimmunol 2004; 147: 141-144.

35. Akiyama H, Barger S, Barnum S, Bradt B, Bauer J, Cole GM et al. Inflammation and Alzheimer's disease. Neurobiol Aging 2000; 21: 383-421.

36. Kaltschmidt B, Uherek M, Volk B, Baeuerle PA, Kaltschmidt C. Transcription factor NF-kappaB is activated in primary neurons by amyloid beta peptides and in neurons surrounding early plaques from patients with Alzheimer disease. Proc Natl Acad Sci USA 1997; 94: 2642-2647.

37. Gillardon F, Kloss A, Berg M, Neumann M, Mechtler K, Hengerer B et al. The 20S proteasome isolated from Alzheimer's disease brain shows post-translational modifications but unchanged proteolytic activity. J Neurochem 2007; 101: 1483-1490.

38. Gregori L, Fuchs C, Figueiredo-Pereira ME, Van Nostrand WE, Goldgaber D. Amyloid beta-protein inhibits ubiquitin-dependent protein degradation in vitro. J Biol Chem 1995; 270: 19702-19708.

39. Mizushima N, Yamamoto A, Matsui M, Yoshimori T, Ohsumi $Y$. In vivo analysis of autophagy in response to nutrient starvation using transgenic mice expressing a fluorescent autophagosome marker. Mol Biol Cell 2004; 15: 1101-1111.

40. Pickford F, Masliah E, Britschgi M, Lucin K, Narasimhan R, Jaeger PA et al. The autophagy-related protein beclin 1 shows reduced expression in early Alzheimer disease and regulates amyloid beta accumulation in mice. J Clin Invest 2008; 118: 2190-2199. 